\title{
outlook
}

\section{One man's meat is another man's poison}

\author{
SSS Science \& Society Series on Food and Science
}

\author{
Jane Wardle \& Lucy J. Cooke
}

\begin{abstract}
"Nothing would be more tiresome than eating and drinking if God had not made them a pleasure as well as a necessity."
\end{abstract}

\section{Voltaire}

$\mathrm{H}$ umans, like many other mammalian omnivores, have strong food-related biases. We tend to like sweet things and dislike bitter tastes; we are suspicious of new foods (neophobia); and we learn what to like and dislike from our experiences with food and the influence of those around us (Rozin \& Vollmecke, 1986). These universal characteristics of food preference and avoidance are likely to have evolved to ensure that our diets are nutritionally adequate and to help us avoid toxins. Nevertheless, it is unclear whether and how food preferences are encoded in our genomes and what role the environment plays in shaping our preferences for particular foods. This question is not only intriguing for researchers, but also has implications for nutrition and health, particularly in the light of the abundance of food available in affluent nations that is feeding an epidemic of obesity, and the ensuing need to teach children how to choose a healthy and balanced diet.

Across the world, humans eat an extraordinary variety of animals and plants; one country's delicacy is sometimes regarded

\section{SSS}

Science \& Society Series on

Food and Science

This article is part of the EMBO reports Science \& Society series on 'food and science' to highlight the role of natural and social sciences in understanding our relationship with food. We hope that the series serves a delightful menu of interesting articles for our readers. with disgust elsewhere. Nevertheless, there are dietary themes across cultures and nations: almost every cuisine has a basic form of carbohydrate- such as potato or rice-and sweet treats. Most diets also feature high-value protein-based foods that indicate social status or are used for celebrations, and many cuisines have different foods for children. Within local cuisines there is further variation, as individuals express their preferences for certain foods. This presents a puzzle for scientists: why does one person love cucumber and another hate it? Is it due to genes, experience, or both? If we are able to answer these questions, how can we use such knowledge to help young children choose a healthy diet that is rich in fruit and vegetables, with less fat and carbohydrate?

\section{These universal characteristics of food preference and avoidance are likely to have evolved to ensure that our diets are nutritionally adequate and to help us to avoid toxins}

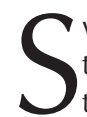
weetness is an indicator of sugar content and therefore calories; a signal that has only lost its meaning somewhat since the invention of low-calorie sweeteners. Unsurprisingly, a preference for sweet tastes seems to be innate in humans. Almost all newborn infants react more positively to sugar solutions than to water, as measured by their facial expressions (Fig 1; Beauchamp \& Moran, 1982). Most infants also show a strong dislike of bitter and sour tastes (Steiner, 1979). A liking for salty tastes is also common, and emerges slightly later in life at around four months of age (Beauchamp et al, 1986). Even infants who

\author{
Within local cuisines there is \\ further variation, as individuals \\ express their preferences for \\ certain foods
}

are exclusively breast-fed show a preference for salted over unsalted cereals at 16-25 weeks of age, despite the fact that breast milk has a low sodium content. This liking for salt persists through early childhood (Beauchamp \& Cowart, 1990) along with the liking for sweetness: infants and children prefer higher concentrations of sugar and salt than adults.

People also avoid foods that they have not encountered before, a trait that is known as 'food neophobia'. It is common in omnivores and has been observed in a diverse range of species including warblers and capuchin monkeys (Greenberg, 1983; Visalberghi \& Addessi, 2000). The adaptive value of avoiding new substances is obvious: it reduces the possibility of poisoning from toxic plants or animals. Interestingly, neophobia is minimal during infancy-when the child's food intake is largely dictated by adults - but it increases rapidly as the child's independence and autonomy increase-perhaps as a protective mechanism once the parents' control of the child's diet decreases. Humans and animals are more likely to accept an unfamiliar food when they observe other members of their species or family eating it and suffering no adverse effects, but new foods are often eaten sparingly at first-again, to minimize potential danger.

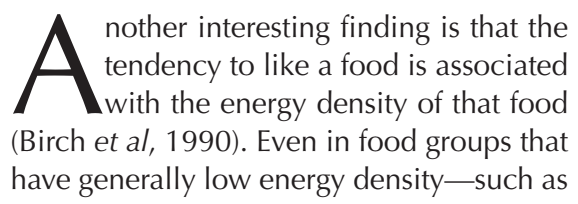



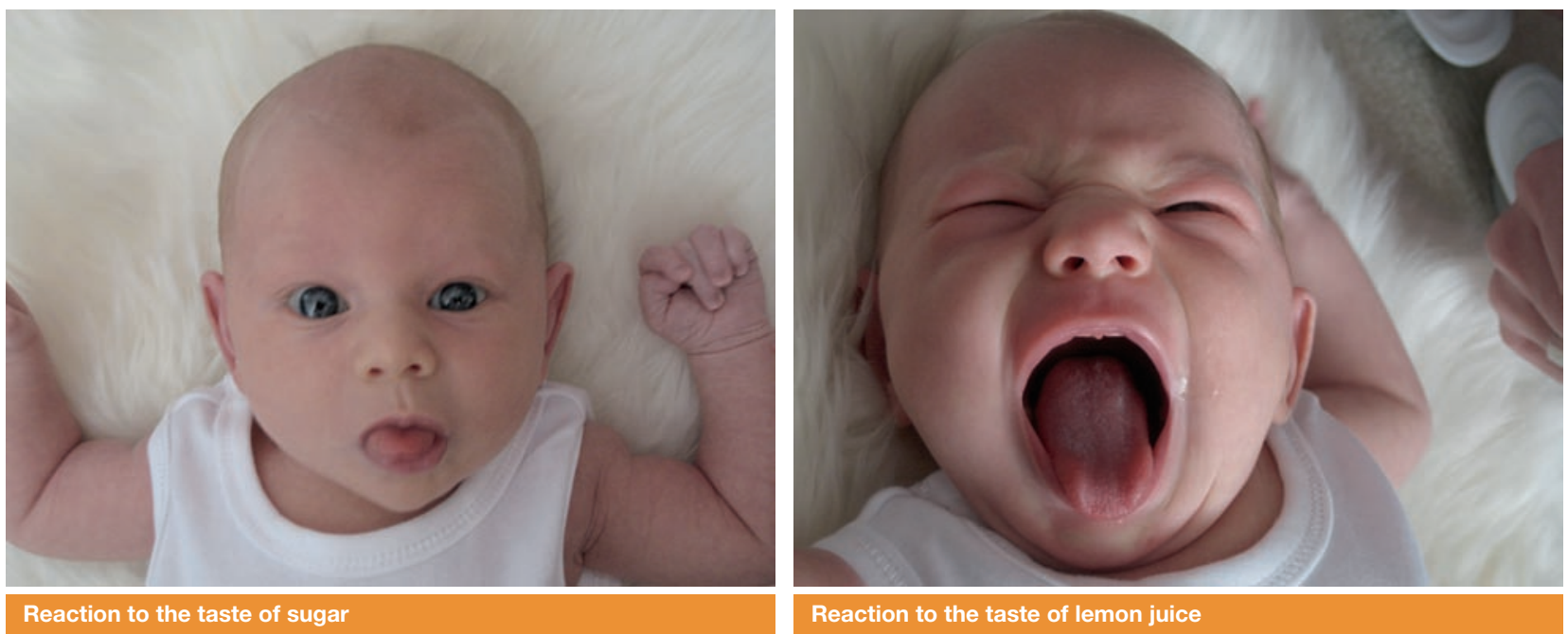

Fig 1 Reactions of a two-week old baby to different tastes.

fruits and vegetables_-children prefer those containing more calories per gram, choosing carrots and peas over spinach and courgettes (Gibson \& Wardle, 2003). As energy density is not a taste per se, such preferences must be learned through experience of the consequences of eating particular foods. This is supported by experiments in which the energy density of soups were modified by the addition of a tasteless starch. Each individual was given high- and low-calorie versions of the soup, and flavour-energy pairings were randomized across individuals. After several days, participants developed a preference for the flavour of the high-energy soup (Booth et al, 1982). A similar effect has been observed in children; after several exposures, they prefer flavours that are associated with higher energy density (Johnson et al, 1991). The adaptive value of this type of 'flavour-consequence learning' in impoverished food environments is clear, as it encourages foraging for foods with higher energy density.

\section{Overall, the evidence from twin studies indicates that genetic differences do not fully account for individual differences in food preferences}

The opposite of learning to like foods with positive nutritional effects is learning to dislike foods that have adverse effects. If animals or humans eat a food-especially a new food-and shortly afterwards experience negative consequences such as nausea or diarrhoea, they often develop a dislike for this particular food. This can persist even if they later learn that the illness was not caused by the food. Seligman called this 'sauce béarnaise syndrome' after a personal experience (Seligman \& Hager, 1972). Studies in rats have shown that learning is associated with taste and not appearance (Wilcoxon et al, 1971). Aversions also seem to be learnt more quickly and overcome less easily than likes, and may persist for decades.

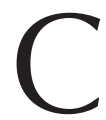
ulture-as a shared experienceand genetics also influence our food preferences. Culture is a source of similarities within groups, as well as differences between them. Children develop dietary habits in accordance with their culture in terms of individual food preferences, combinations of ingredients, preparation methods, and times at which to eat particular meals. Distinctive and traditional spices and seasoning combinations can also facilitate the acceptance of new foods if these signal familiar and well-liked flavours (Pliner \& Stallberg-White, 2000). Even flavours that are often innately disliked, such as chilli, or potentially disgusting items, such as insects, might be liked if they are part of the cuisine of the culture in which a child is growing up (Rozin \& Schiller, 1980).

Globalization of the food supply creates an increasing homogeneity of food across countries. High-fat foods, such as pizza and French fries, and sweet foods, such as chocolate or cookies, are in the top ten favourite foods of children in the UK, France, Spain, Germany and the USA
(Cooke \& Wardle, 2005). Few studies have investigated food preferences in populations outside Europe and North America, but the spread of fast-food chains globally suggests that this homogenization of tastes might expand elsewhere.

Although it is clear that many crosscultural differences are learnt from exposure and familiarity, there might also be genetic variations - such as those between different ethnic groups-that affect the acceptance and/or use of certain foods. One wellknown example is lactose intolerance. After weaning, the gene that encodes the enzyme lactase - which breaks down lactose-is often 'switched off', impairing the digestion of lactose-containing, fresh dairy products. Some genetic variants, however, allow lactase production to continue, and these adults can therefore still digest milk or milk products. Lactase-persistence genetic variations are common in Europe and East Africa, but less so in China and Japan, countries where dairy consumption has traditionally been low.

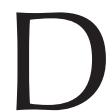
espite the universal nature of food preferences, there is individual variation in favourite foods and, even more so, in foods that are disliked. Jack Spratt and his wife from the traditional English nursery rhyme are by no means an exception:

\section{"Jack Spratt would eat no fat, his wife would eat no lean, and so betwixt the two of them, they licked the platter clean."}

Only a proportion of food dislikes seem to originate from specific and memorable 


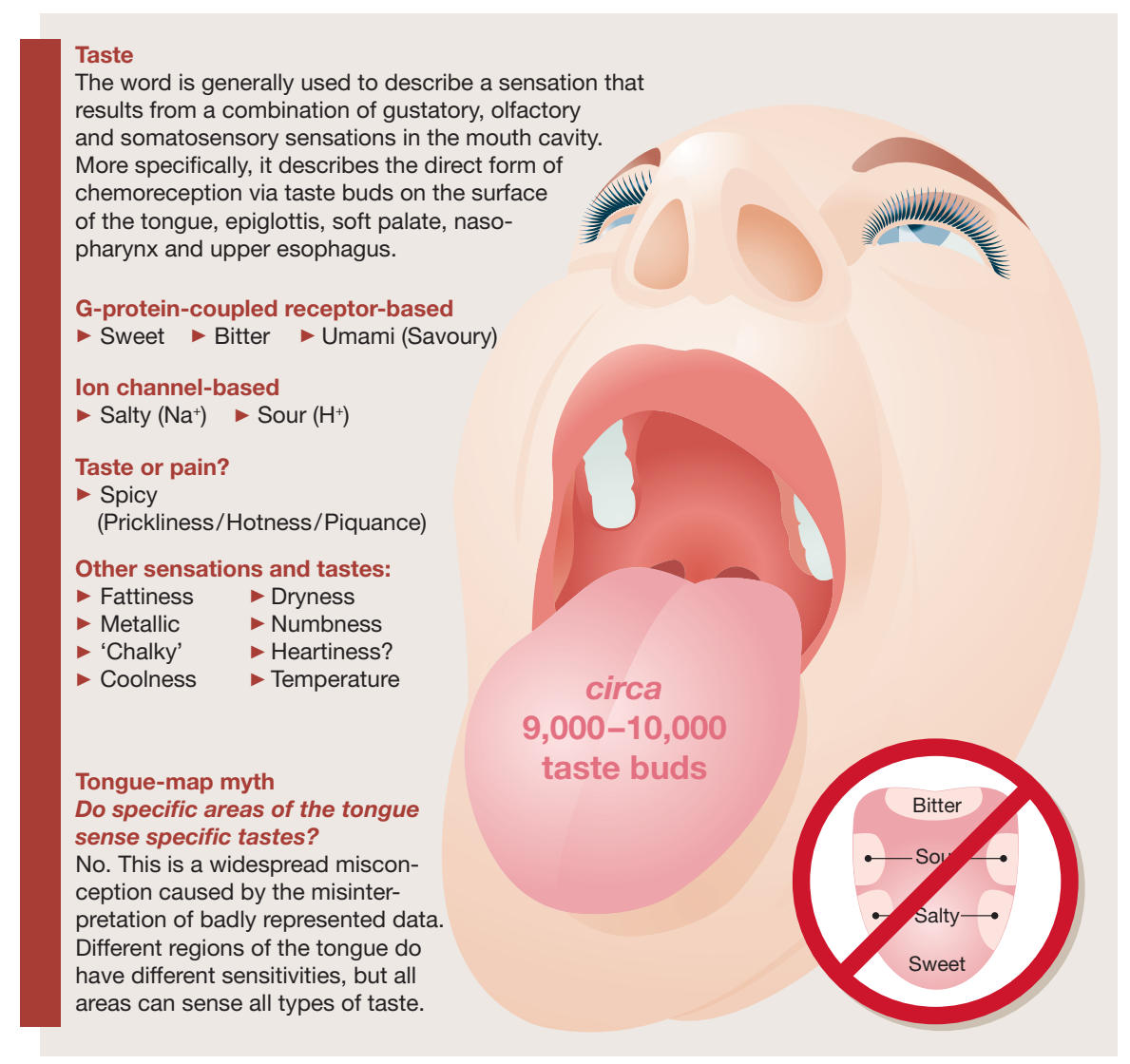

Fig 2 The combination of taste and olfactory receptors determine how we taste food.

aversive experiences, many of which occur early in life. The early development and stability over time of these preferences, along with the absence of obvious environmental causes, implicates genetic differences in their causation.

Taste receptors for sweet, sour, bitter, salty, umami (savoury) and possibly fat, in combination with nasal and retronasal olfactory receptors create the complex tastes of foods (Fig 2). Genetic differences in taste receptors are therefore obvious candidates for causing differences in food preferences, although associations between receptors and hedonic responses to food have not been well mapped so far.

Quantitative genetics provides a methodology with which to assess the 'bottom line' of genetic influence. If certain traits - in this case, food preferences-are assorted according to the degree of geneticrelatedness between individuals, it would support the notion that genes explain differences in taste preferences. Heritability, therefore, is a factor that can be used to identify candidate genes; if heritability is low, the cause of individual differences in food preference is likely to be environmental.

The results of studies of family food preferences have, in general, provided little support for genetic explanations. Although parents and their children share $50 \%$ of their genes, correlations between their food preferences are modest (Rozin, 1991). This is similar to the level of correlation found between spouses. Parents and children are different ages and have had different rearing experiences, which might partly explain the differences in their food preferences.

$\mathrm{T}$ win studies are more accurate measures of genetic influence, as monozygotic (MZ) twins are genetically identical and dizygotic (DZ) twins share on average $50 \%$ of their genes. Heritability is estimated from the extent to which the similarity between $M Z$ pairs is greater than that between DZ pairs. Many twin studies have failed to provide evidence for a genetic contribution to food preferences (Faust, 1974), whereas others have found positive effects in only one or two foods (Falciglia \& Norton,
1994). However, most of these studies have had small sample sizes and assessed only small numbers of foods. One large study used a sample of 428 young twins and an extensive list of foods, which were grouped into four categories based on the similarity of preferences within groups (Breen et al, 2006). The results found low heritability of preferences for sweet dessert foods (0.20) and vegetables (0.37), moderate heritability for fruits $(0.51)$ and high heritability for protein foods (0.78). These differences are intriguing, but they are yet to be replicated so conclusions must be drawn tentatively. The low heritability of preferences for sweet foods is unsurprising as liking for sweets is widespread. More surprising was the high heritability of preferences for protein foods such as meat and fish, which had not been reported before. Genetic influences might be influential here through umami responsiveness. Overall, the evidence from twin studies indicates that genetic differences do not fully account for individual differences in food preferences.

nother possible contributor to taste
preferences is neophobia. Neo-
phobic children are less likely to accept certain foods than their moreadventurous peers (Nicklaus et al, 2005). A large pediatric twin study estimated the heritability of neophobia as $78 \%$ (Cooke et al, 2007). It is possible that heritable differences in neophobia influence the number of foods that a person dislikes, by controlling their willingness to eat unfamiliar foods.

Although humans are sensitive to bitter tastes from birth, there is variation in bitterness perception, especially as the ability to taste the compounds phenylthiocarbamide (PTC) and 6-n-propylthiouracil (PROP) is inherited. A specific genetic locus has been identified-taste receptor, type 2, member 38; TAS2R38-that is associated with the number of fungiform papillae and taste buds on the anterior tongue. Although there are ethnic variations, approximately $30 \%$ of the global population are nontasters and $70 \%$ are tasters, of whom just over onethird are 'supertasters' - individuals who are extremely sensitive to these compounds.

It is assumed that PROP tasters are more sensitive than nontasters to bitterness. Cruciferous vegetables, such as broccoli, have attracted attention because they contain high levels of bitter-tasting glucosinolate compounds, but research findings in this area have been equivocal. Although 
Drewnowski et al (1999) found that young supertaster women had a lower liking for several cruciferous vegetables, studies in elderly women and college students found no differences (Mattes \& Labov, 1989). In child PROP tasters, lower acceptance of raw but not cooked broccoli was observed in one comparison (Keller et al, 2002). Another study found a higher intake and liking of bitter-tasting foods - such as olives and broccoli-in nontasters in a free-choice test (Bell \& Tepper, 2006). However, other studies have found no differences in vegetable intake or preference between PROP tasters and nontasters (Anliker et al, 1991).

\section{It seems clear that an individual's experience with food is capable of overriding innate predispositions}

It is possible that research focusing on cruciferous vegetables - which most children dislike-has obscured other differences in preference. PROP taster status has been linked with acceptance of a variety of other foods including citrus fruit, alcohol, coffee, dark chocolate, milk and dairy foods, green tea and soy products, as well as sweet or salty tastes and fats (Anliker et al, 1991), although the explanation for this in terms of taste properties is yet to be identified.

Efforts to identify genes that are related to food preferences have generally been unsuccessful, although variation in sensitivity to umami has recently been linked to polymorphisms on the TAS1R1 and TAS1R3 genes (Chen et al, 2009). Umami has been associated with monosodium-glutamate sensitivity specifically, but it might be linked with the liking of other savoury foods, which has been shown to be highly heritable.

I t seems clear that an individual's experience with food is capable of overriding any innate predispositions. These experiences are the what, where, how often and with whom of food consumption. Twin studies are used not only to determine heritability, but also to distinguish between 'shared environment' effects-which tend to cause individuals who grew up in the same household to behave like one anotherand 'non-shared environment' effects. Shared environment effects are implicated when twins-MZ or DZ-are more phenotypically similar than the heritability of the trait in question can account for. Yet, it requires large studies to reliably determine the extent of the environmental influence. Breen and colleagues (2006) have indicated that shared environment effects are important; being reared in the same home contributed significantly to the similarity between children. Just as the evidence of heritability provides an impetus for identifying the relevant genes, evidence for shared environment effects provides an impetus for identifying the environmental features that influence shared behaviour or preferences.

One of the strongest environmental influences on food preference is taste. This can affect an individual's likes and dislikes from the earliest stages of life; the maternal diet can influence the child in utero. In a series of studies at the Monell Chemical Senses Center, USA, Julie Mennella and her colleagues demonstrated this phenomenon by assigning pregnant women who were planning to breastfeed to one of three groups. Women were asked to drink carrot juice regularly either in the last trimester of pregnancy, while breastfeeding, or not at all. Babies born to the mothers in either of the carrot juice groups had less negative responses to carrots during weaning, and were perceived to like them more by their mothers than babies of mothers in the control group (Mennella et al, 2001). Similar results have been documented in rats, dogs, sheep, rabbits and piglets.

Evidence for the ability of exposure to promote liking for certain foods has been building over the past three decades. Surveys in children of food consumption and preferences have linked early taste experiences to subsequent food acceptance (Cooke et al, 2004), which is consistent with an exposure effect. Experimental studies have also shown that exposure increases liking and acceptance in animals, children (Sullivan \& Birch, 1990) and adults (Pliner et al, 1993). One study that compared children's acceptance of three varieties of a new food-plain, salted or sugared tofushowed that children preferred whichever variety they had been exposed to earlier (Sullivan \& Birch, 1990).

These findings have been replicated in the outside world. In one study, school children were randomly divided into three groups: exposure to the food (red pepper), exposure plus reward, or no exposure. After eight days, the children exposed to red pepper had significantly increased their liking and intake of it, compared with the control group (Wardle et al, 2003b). The same effects were achieved when the intervention was delivered by mothers who had been taught exposure feeding techniques. When offered a vegetable that they had initially disliked, children in the experimental group showed a greater increase in liking and intake after 14 days than those in the control groups, who had received no treatment or had been given leaflets about healthy eating (Wardle et al, 2003a).

$\mathrm{n}$ animals, food preferences are thought to be socially transmitted: the sight of members of their own species eating, or even the smell of food on their breath can encourage consumption. In one study, lambs were exposed to three treatments: they ate a new food with their mother, observed her doing so but were unable to eat it themselves, or the mother ate the food out of their sight. Lambs that were with their mother while she was eating showed a stronger preference for the food in a subsequent test, even if they had not eaten the food themselves (Saint-Dizier et al, 2007).

These modelling effects have also been observed in humans. In one study, children drank different flavours of new drinks while watching a video of a model expressing a like or dislike of the same drink (Baeyens et al, 1996). The children were found to prefer the flavour that the model had liked. This suggests that in the home, if parents, or better still peers, show that they like a food the child will be more inclined to taste and accept it.

\section{...serving new or less-liked foods in a happy mealtime atmosphere will increase the likelihood of a positive appreciation of those foods in the future}

Observational and experimental studies indicate that modelling is an effective tool for influencing preferences. In one study, the 'target' children were seated with peers who had opposite preferences to them. On the first day, the target children had to choose between a preferred and non-preferred vegetable. On the next three consecutive days, the peers chose their preferred vegetable first. The target children were more likely to eat a vegetable that they did not like after observing another child eating it (Birch, 1980). Conversely, it is likely that food aversions can also be learnt through observation. Although there have been no studies 
demonstrating this in humans, it has been seen in animals. Mason and colleagues (1984) found that blackbirds that had observed others becoming ill after consuming food from a yellow cup avoided eating from yellow cups thereafter. Social learning presumably operates as a demonstration of safety and reassurance when a food is harmless, or notification of potential danger when a food should be avoided.

\section{Of course, preference is only an issue when there is something to prefer. Being choosy is a luxury born of plenty}

The context of an individual's first experience with a new food could contribute to their willingness to eat it in future. A negative physiological state such as tiredness, illness or negative mood by parents are thought to impair children's enjoyment of eating (Wardle et al, 2001) and might also adversely affect hedonic reactions to new foods. Being hungry at the time of first exposure might result in a more-positive evaluation, although this might be more important when the food is energy-dense (Gibson \& Wardle, 2001). Coercive feeding practices, which create a tense and negative atmosphere at mealtimes, might therefore impair the enjoyment of food (Galloway et al, 2006). The reverse is also true: giving food as a reward or linking eating with attention from adults has been shown to increase children's liking, compared with nonsocial eating (Birch et al, 1980).

The take-home message seems to be that serving new or less-liked foods in a happy mealtime atmosphere will increase the likelihood of a positive appreciation of those foods in the future. The determinants of food preferences, however, are not fully understood and although genetic factors are widely thought to be involved, the extent of their influence remains unknown. What follows is therefore speculation, rather than science.

ince taste preferences are malleable and change through experience, it $\mathcal{Y}$ is easy to imagine how individual and sometimes eccentric food preferences develop. If the family's principal food provider dislikes bananas, they will be bought and served infrequently, if at all. A child in this hypothetical family would be relatively unfamiliar with bananas, which, when combined with an inherited tendency to dislike fruit and the knowledge that bananas are not highly rated by their parent or caregiver, may give the impression that they are not good to eat. However, if this child is placed in an environment in which bananas are frequently and enthusiastically consumed, acceptance is likely to develop. Thus, genes are expressed in different environments to produce different food preference phenotypes.

Even when the food provider likes the food that they are offering, the child may express surprise when given a new flavour, and this might be interpreted as rejection or dislike by the parent. A negative reaction to an unfamiliar food in infants-with the possible exception of very soft, sweet foods - is to be expected, irrespective of the innate palatability of the food being offered (Forestell \& Mennella, 2007). Some research suggests that children need to taste a new food at least ten times before they change their preference (Wardle et al, 2003a), especially if its initial palatability is low. Mothers typically cease to offer foods that have been rejected on three or more occasions (Carruth et al, 2004) and as a result the necessary level of exposure required to create acceptance might not be reached. A child's 'dislike' of bananas might become family lore, internalized by parents and child and never tested again.

We might celebrate our idiosyncratic food likes and dislikes as evidence that we are original and special; meeting another person who shares an idiosyncratic dislike for a particular food creates a bond, especially on a first date. When the dislike is for a popular food, such as chocolate, rather than for a commonly rejected food, such as green vegetables, the effects are even stronger. This extends to our offspring; we might view our child's rejection of sweets or liking for black olives as pleasing indications of their sophisticated palate and reflections of our enlightened parenting.

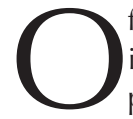
$f$ course, preference is only an issue when there is something to prefer. Being choosy is a luxury born of plenty. In today's food environment, you can like bananas and I can choose not to because I can always eat something else. Not long ago, this choice did not exist, which may have been advantageous from a health point of view. Now, when there is always a palatable alternative, making healthy choices is harder than ever and we might evaluate healthy foods more negatively simply because of this. Another issue concerns the expectation of pleasure from food. This was once the preserve of only the most prosperous, but is now normal in Western societies. What was once merely fuel to enable us to stay alive has become a source of enjoyment, comfort and even entertainment.

The reason that fruit is sometimes consumed less frequently than recommended might be less to do with dislike-since we know that children rate fruit highly-and more to do with the alternatives on offer. Few children would choose an apple as a dessert when they know that a chocolate mousse lurks in the fridge. In light of the obesity epidemic that is ongoing in developed and many developing nations - which is, at least partly, caused by a diet rich in carbohydrates, fat and protein-knowledge about how we acquire and modify food preferences is crucial. It could be used to develop programmes to teach people, particularly children, to eat more healthily.

\section{Few children would choose an apple as a dessert when they know that a chocolate mousse lurks in the fridge}

The sheer quantity and variety of food that is available to us enables us to waste perfectly edible and nutritious parts of the foods that we eat. This might be simply because we are too squeamish to eat certain foodstuffs or parts of animals, or because we prefer not to eat the skin of fruit or vegetables. In the future, if we want to conserve the planet's resources we might have to adapt and eat different, sometimes less attractive foods. It is therefore a good thing that food preferences seem to be more malleable and less hard-wired than has been previously assumed.

\section{CONFLICT OF INTEREST}

The authors declare that they have no conflict of interest.

\section{REFERENCES}

Anliker JA, Bartoshuk L, Ferris AM, Hooks LD (1991) Children's food preferences and genetic sensitivity to the bitter taste of 6-n-propylthiouracil (PROP). Am / Clin Nutr 54: 316-320

Baeyens F, Kaes B, Eelen P, Silverans P (1996) Observational evaluative conditioning of an embedded stimulus element. Eur / Soc Psychol 26: $15-28$ 
Beauchamp GK, Cowart BJ (1990) Preference for high salt concentrations among children. Devel Psychol 26: 539-545

Beauchamp GK, Cowart BJ, Moran M (1986) Developmental changes in salt acceptability in human infants. Dev Psychobio/ 19: 17-25

Beauchamp GK, Moran M (1982) Dietary experience and sweet taste preference in human infants. Appetite 3: 139-152

Bell KI, Tepper BJ (2006) Short-term vegetable intake by young children classified by 6-n-propylthoiuracil bitter-taste phenotype. Am J Clin Nutr 84: 245-251

Birch LL (1980) Effects of peer models food choices and eating behaviors on preschoolers food preferences. Child Devel 51: 489-496

Birch LL, McPhee L, Steinberg L, Sullivan S (1990) Conditioned flavor preferences in young children. Physiol Behav 47: 501-505

Birch LL, Zimmerman SI, Hind H (1980) The influence of social-affective context on the formation of childrens food preferences. Child Devel 51: 856-861

Booth DA, Mather P, Fuller J (1982) Starch content of ordinary foods associatively conditions human appetite and satiation, indexed by intake and eating pleasantness of starch-paired flavours. Appetite 3: 163-184

Breen FM, Plomin R, Wardle J (2006) Heritability of food preferences in young children. Physiol Behav 88: 443-447

Carruth BR, Ziegler PJ, Gordon A, Barr SI (2004) Prevalence of picky eaters among infants and toddlers and their caregivers' decisions about offering a new food. J Am Diet Assoc 104 (Suppl): 57-64

Chen QY, Alarcon S, Tharp A, Ahmed OM, Estrella NL, Greene TA, Rucker J, Breslin PA (2009) Perceptual variation in umami taste and polymorphisms in TAS1R taste receptor genes. Am J Clin Nutr 90: 770S-779S

Cooke LJ, Haworth CM, Wardle J (2007) Genetic and environmental influences on children's food neophobia. Am J Clin Nutr 86: 428-433

Cooke LJ, Wardle J (2005) Age and gender differences in children's food preferences. Br J Nutr 93: 741-746

Cooke LJ, Wardle J, Gibson EL, Sapochnik M, Sheiham A, Lawson M (2004) Demographic, familial and trait predictors of fruit and vegetable consumption by pre-school children. Public Health Nutr 7: 295-302

Drewnowski A, Henderson SA, Levine A, Hann C (1999) Taste and food preferences as predictors of dietary practices in young women. Public Health Nutr 2: 513-519

Falciglia GA, Norton PA (1994) Evidence for a genetic influence on preference for some foods. J Am Diet Assoc 94: 154-158
Faust J (1974) A twin study of personal preferences. J Biosoc Sci 6: 75-91

Forestell CA, Mennella JA (2007) Early determinants of fruit and vegetable acceptance. Pediatrics 120: 1247-1254

Galloway AT, Fiorito LM, Francis LA, Birch LL (2006) 'Finish your soup': counterproductive effects of pressuring children to eat on intake and affect. Appetite 46: 318-323

Gibson EL, Wardle J (2003) Energy density predicts preferences for fruit and vegetables in 4-year-old children. Appetite 41: 97-98

Gibson EL, Wardle J (2001) Effect of contingent hunger state on development of appetite for a novel fruit snack. Appetite 37: 91-101

Greenberg R (1983) The role of neophobia in determining the degree of foraging specialization in some migrant warblers. Am Nat 122: 444-453

Johnson SL, McPhee L, Birch LL (1991) Conditioned preferences: young children prefer flavors associated with high dietary fat. Physiol Behav 50: 1245-125

Keller KL, Steinmann L, Nurse RJ, Tepper BJ (2002) Genetic taste sensitivity to 6-n-propylthiouracil influences food preference and reported intake in preschool children. Appetite 38: 3-12

Mason JR, Arzt AH, Reidinger RF (1984) Comparative-assessment of food preferences and aversions acquired by blackbirds via observational-learning. Auk 101: 796-803

Mattes R, Labov J (1989) Bitter taste responses to phenylthiocarbamide are not related to dietary goitrogen intake in human beings. J Am Diet Assoc 89: 692-694

Mennella JA, Jagnow CP, Beauchamp GK (2001) Prenatal and postnatal flavor learning by human infants. Pediatrics 107: E88

Nicklaus S, Boggio V, Issanchou S (2005) Food choices at lunch during the third year of life: high selection of animal and starchy foods but avoidance of vegetables. Acta Paediatr 94: 943-951

Pliner P, Pelchat M, Grabski M (1993) Reduction of neophobia in humans by exposure to novel foods. Appetite 20: 111-123

Pliner P, Stallberg-White C (2000) "Pass the ketchup, please": familiar flavors increase children's willingness to taste novel foods. Appetite 34: 95-103

Rozin P (1991) Family resemblance in food and other domains: the family paradox and the role of parental congruence. Appetite 16: 93-102

Rozin P, Schiller D (1980) The nature and acquisition of a preference for chili pepper by humans. Motiv Emotion 4: 77-101

Rozin P, VollmeckeTA (1986) Food likes and dislikes. Annu Rev Nutr 6: 433-456
Saint-Dizier H, Levy F, Ferreira G (2007) Influence of the mother in the development of flavoredfood preference in lambs. Devel Psychobiol 49: 98-106

Seligman ME, Hager JL (1972) Sauce-bearnaise syndrome. Psychol Today 6: 59

Steiner JE (1979) Human facial expressions in response to taste and smell stimulation. $A d v$ Child Dev Behav 13: 257-295

Sullivan SA, Birch LL (1990) Pass the sugar, pass the salt: experience dictates preference. Devel Psychol 26: 546-551

Visalberghi E, Addessi E (2000) Seeing group members eating a familiar food enhances the acceptance of novel foods in capuchin monkeys. Anim Behav 60: 69-76

Wardle J, Cooke LJ, Gibson EL, Sapochnik M, Sheiham A, Lawson M (2003a) Increasing children's acceptance of vegetables; a randomized trial of parent-led exposure. Appetite 40: 155-162

Wardle J, Guthrie CA, Sanderson S, Rapoport L (2001) Development of the Children's Eating Behaviour Questionnaire. J Child Psychol Psychiatry 42: 963-970

Wardle J, Herrera ML, Cooke L, Gibson EL (2003b) Modifying children's food preferences: the effects of exposure and reward on acceptance of an unfamiliar vegetable. Eur J Clin Nutr 57: 341-348

Wilcoxon HC, Dragoin WB, Kral PA (1971) Illness-induced aversions in rat and quail: relative salience of visual and gustatory cues. Science 171: 826
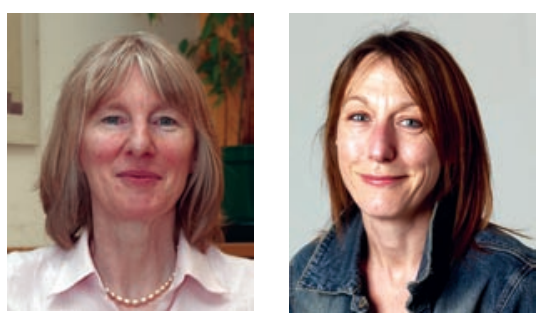

Jane Wardle [left] and Lucy J. Cooke are at the Health Behaviour Research Centre, Department of Epidemiology and Public Health, University College London, UK. E-mail:j.wardle@ucl.ac.uk

Received 16 August 2010; accepted 22 September 2010; published online 15 October 2010

EMBO reports (2010) 11, 816-821.

doi:10.1038/embor.2010.161 